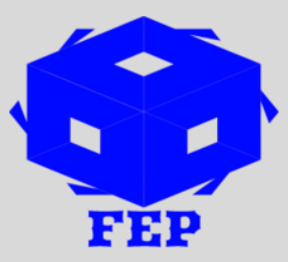

\title{
THE RELATIONSHIP BETWEEN CRUDE OIL PRICES AND STOCK MARKET: THE INDIAN CASE
}

Premkumar Rajnathan ${ }^{1}$

${ }^{1}$ State Commerce College, Tamil Nadu, India

*Corresponding Author: Rajnathan

Article Received: 08-10-19
Accepted: 30-12-19

Published: 10-01-20

Licensing Details: Author retains the right of this article. The article is distributed under the terms of the Creative Commons Attribution-Non Commercial 4.0 License (http://www.creativecommons.org/licences/by-nc/4.0/) which permits non-commercial use, reproduction and distribution of the work without further permission provided the original work is attributed as specified on the Journal open access page.

\begin{abstract}
Crude oil is influencing every productivity activity of human life either directly or indirectly. The prices of crude oil also influence the international financial markets. This influence connects the oil market with that of capital market since stock market provides it necessary resources for investment and financing the production. In this study, the objective was to test the relationship between crude oil prices and selected sectors of Indian economy. Furthermore, the study also tests the effects of international crude oil prices on the Indian stock exchange market. The main objective was to test the conditional correlation of the crude oil price and equity returns of selected sectors of the Indian economy as well as the performance indicators of the Indian stock market using bivariate volatility models.
\end{abstract}

Keywords: Oil Prices, Stock Market, Causality, Cointegration, Dynamic Correlation

\section{INTRODUCTION}

The price of crude oil is important variable for economic policy makers in most countries having oil as the main energy source. There are several events which occurs randomly but influence crude oil prices. Examples of such events includes exchange rate movements, political or geopolitical aspects, industrial production variations, economic growth, availability of oil stocks, and the weather. The variations in crude oil prices cause direct influence in the International financial markets these variations bring changes in foreign trade, in productive activities, and investment. Hence, it can be said that crude oil market is 
highly important for economic development and present directly or indirectly in most productive activities. The crude oil is present in many sectors of the economy. Hence, the crude oil price movement provides resources for investment and financing of production. Furthermore, the crude oil price movement is considered a relevant influence factor to the stock market expectations or in equity prices determinations to the economic activities in general.

There are several studies which investigated the crude oil and financial market performance connection. Mostly, such studies looked at the stochastic process which represent the movements or the returns of these time series to obtain price expectations. In recent years, there are several studies conducted on the topic. For example, Cheng (1986) tested the oil prices on the U.S. stock market and found that the crude oil prices are not related to the equity pricing traded in the U.S. stock exchange market. Another study by Ferson and Harvey (1995) investigated the influence of crude oil price on different international stock markets and found that in different market, the crude oil prices have varying impact. A study by Jones and Kaul (1996) also tested the crude oil price and stock market performance in different developed countries stock exchange markets. The findings were that oil prices do have significant influence on the performance of these stock markets. Another study by Faff and Brailsford (1999) tested the effect of oil prices on stock market returns in the Australian market using the augmented market model. The results show that in that particular market, there is insignificant effects on stock performance.

Similar relationship is investigated by Sadorsky (1999) using a vector autoregression. The results show that crude oil prices return and volatility are important for the economic activity but the economic movements have insignificant influence on crude oil prices. Another study by Papapetrou (2001) investigated the interaction of stock prices and oil prices and Greek macroeconomic variables showing that changes in oil prices have direct and significant influence on economic activity. Another study by Sadorsky (2003) investigated the crude oil price on volatility in technology sector. The results shows that crude oil prices have significant influence on volatility of technology sector which is listed on the U.S. stock market. A study by Maghyereh (2004) also investigated similar relationship and reported that crude oil prices shocks are insignificantly related to the stock index returns of developing countries.

A study by Basher and Sadorsky (2006) investigated the relationship between crude oil price changes and stock prices utilizing the equity pricing model. The findings shows that crude oil price change and stock prices are significantly correlated. Another study by Nandha and Faff 
(2008) investigated the oil prices and stock market return expectations relationship. The findings were that there is negative relationship between oil prices and stock market returns. A study by Tansuchat et al., (2010) tested the influence of crude oil and stock index return by utilizing the multivariate GARCH model. The results show that crude oil and financial market dependence really occurs. Another study by Huang, et al., (2011) showed that there is significant interdependence between crude oil prices and stock indexes. A study by Farahani, et al., (2012) investigated the similar relationship and showed that oil prices and economic growth has insignificant causal relationship. Another study by Bhunia (2012) investigated the relationship between crude oil prices and Indian stock market index by utilizing the cointegration and causality tests. The results showed that cointegration between crude oil prices and the indices was partially found. Another study by Ratti and Hasan (2013) also investigated similar relationship. The results showed that crude oil prices return and volatility on return had negative relationship. In this study, the objective is to test the relationship between crude oil prices and selected sectors of the Indian economy. The study also aims to test the influence of international crude oil prices on the Indian stock market.

\section{THE METHODOLOGY}

\section{The Sample Used}

We used a daily closing equity prices of selected companies listed in the Indian stock exchange market and used close quotations of the stock market index and the Brent crude oil type price negotiated in the London market. All data is recorded in US\$. The duration of the sample utilized is from $4^{\text {th }}$ June 2007 to $8^{\text {th }}$ August 2011.

Table 1

Selected Firms and Industrial Sector

\begin{tabular}{clll}
\hline S. No & SELECTED FIRM & NEGATIATION CODE & ECONOMIC SECTOR \\
\hline 01 & Firm 1 & ALLL3 & Transport and Logistics \\
02 & Firm 2 & AMBEV4 & Beverages \\
03 & Firm 3 & CMIG4 & Electric \\
04 & Firm 4 & CSNA3 & Steel Industry \\
05 & Firm 5 & CYRE3 & Civil Construction \\
06 & Firm 6 & ITUB4 & Bank and Finance \\
07 & Firm 7 & PCAR4 & Foods Retailers \\
08 & Firm 8 & PETR4 & Petroleum \\
09 & Firm 9 & VALE5 & Mining \\
\hline
\end{tabular}

The firms which are part of the sample used in the present study were selected according to their average financial volume traded during last 6 months of the studied period. The firms were selected from selected sectors of the Indian economy according to the classification 
structure mentioned by the stock exchange. The firms from each sector were selected based on its biggest financial volume among all other firms from each sector selected. From each sector of the Indian economy, the firm with the greatest financial volume is selected. The firms we selected are listed in table 1.

Table 2

Returns Time Series Statistical Summary

\begin{tabular}{llllllllllll}
\hline Statistics & IBVSP & ALLL & AMBV & CMIG & CSNA & CYRE & ITUB & PCAR & PETR & VALE & BRENT \\
\hline Mean & 0.0006 & -0.0006 & 0.0007 & 0.0006 & 0.00015 & -0.0001 & 0.0005 & 0.00078 & 0.00015 & 0.0006 & 0.0005 \\
Median & 0.0055 & 0.0009 & 0.0006 & 0.0055 & 0.0009 & -0.0055 & -0.0015 & 0.0019 & 0.0017 & 0.0055 & 0.0015 \\
13Maximum & 0.5555 & 0.6565 & 0.5555 & 05555 & 0.5555 & 0.6565 & 0.5555 & 0.5555 & 0.5555 & 0.5155 & 0.1515 \\
Minimum & -0.1677 & -0.6551 & -0.5566 & -0.5155 & -0.5565 & -0.6565 & -0.6655 & -0.5555 & -0.5555 & -0.1006 & -0.5555 \\
Std. Dev. & 0.0555 & 0.0655 & 0.0195 & 0.0109 & 0.0555 & 0.0551 & 0.0665 & 0.0555 & 0.0666 & 0.0555 & 0.0181 \\
Skewness & -0.1518 & 0.1555 & -0.6566 & -0.5555 & -0.1198 & -0.0656 & 0.1511 & 0.5555 & -0.1511 & -0.7878 & 0.0986 \\
Kurtosis & 10.6650 & 15.0657 & 9.5755 & 9.5887 & 9.7859 & 8.7816 & 10.6689 & 8.1505 & 7.6575 & 8.1156 & 8.9597 \\
& & & & & & & & & & & \\
JB & 5516.5 & 5507.9 & 1870.7 & 5068.7 & 1975.5 & 1655.1 & 5605.1 & 1156.8 & 965.6 & 1157.1 & 1511.5 \\
p-value & 0.0000 & 0.0000 & 0.0000 & 0.0000 & 0.0000 & 0.0000 & 0.0000 & 0.0000 & 0.0000 & 0.0000 & 0.0000 \\
& & & & & & & & & & & \\
ADF test & -0.9668 & -0.9055 & -1.1568 & -1.0570 & -0.9585 & -0.8995 & -0.8855 & -0.9665 & -0.9550 & -1.0550 & 0.0000 \\
p-value & -50.57 & -59.05 & -55.99 & -55.85 & -50.58 & -58.97 & -58.56 & -50.81 & -59.90 & -55.89 & 0.0000 \\
& & & & & & & & & & & \\
No. Obs. & 989 & 989 & 989 & 989 & 989 & 989 & 989 & 989 & 989 & 989 & 989 \\
\hline
\end{tabular}

Table 2 provide statistical summary of all-time series data utilized in the present work. The table also present information about normality and stationarity of the data. For testing the normality, Jarque-Bera test was used; while, for testing the stationarity, the Augmented Dickey Fuller test is utilized. Thus table 2 provide details about each variable's averages and median which shows that thye are close to zero with small variations. The descriptive statistics for the returns time series as provided in the table 2 shows that there is very low level of average which is close to zero for the crude oil and all equity selected. The highest earning per stock is $32.7 \%$ while the least earning per stock is minus $30 \%$. The stock which shows greatest volatility of return are obtained from standard deviation was CYRE 3 while the stock with the lowest standard deviation is AMBV and AMBEV4. The respective standard deviations were between 0.045 and 0.026 . Another feature of the financial assets or commodities is the high kurtosis which shows that data has fat tails distributions. Some skewness are positive while other are negative thus it shows that time series do not present a similar behavior or pattern. The Jarque-Bera test shows that the normality assumption of all returns time series analyzed could not only be accepted as the p value is close to zero. The Unit root ADF test shows that there is considerable negative t statistics minus 30 for every return series analyzed which shows that all returns time series studies could be assumed 
stationarity. The next section presents the methodological details of the present study based on the above data for answering the research question.

\section{METHODOLOGICAL APPROACH}

First we tested the cointegration for testing the relationship between Brent crude oil prices return and the selected firm stock returns. Two variables are found to be cointegrating if their linear combination is stationarity which states a long run relationship between these variables. Some alterantive to cointegration tests exist which shows the long-run relationship between these variables. For example, Engle-Granger test which was proposed by Engle and Granger (1987). The procedure is that if cointegration is found between two variables, it is required to conduct error correction mechanisms for estimating the VAR model. In present study, the causality of crude oil prices returns on equity prices return were studied. It is important to note that correlation does not imply a causal relationship between variables, the causality generally refers to the predictive power of lagged variables of a regressor. Hence, if relationship between crude oil prices and stock markets returns found, it is the equities selected and the BMF and Bovespa index, it can implies that the crude oil prices returns time series can be used as a useful forecaster for stock market returns. The concept is known as Granger causality as introduced by Granter back in 1969. The causality test in this study permits to infer that the regressor is an interesting variable used as a forecaster of the response variable in question or in other words known as exogenous variable. The test statistics for the Granger causality hypothesis is Fstatistics provided by the Wald statistics for the joint hypothesis of each one of the regression model parameters included in the VAR model to be equal to zero.

For achieving the research objective, stochastic models for volatility and conditional correlations were used as from the closing quotations of selected equity returns and crude oil prices returns. Time series related problems are taken in to consideration including normality which was not fully observed in the data. For estimating the variance and covariance, bivariate GARCH models are implemented. The GARCH model applied here is the VECH diagonal. We implemented two bivariate models for estimating the variance or volatility and covariance. The second model for the average was the VEC. The vector autoregressive model (VAR) appears to be adequate in efficient markets. In case, efficient market hypothesis cannot be hold true, we can use cointegration variables to be included in the VAR model. In present study, all bivariate models, the VEC model was initially estimated for the average. In situation where obtained estimates were not satisfactory means estimated parameters were statistically insignificant, alternatively, we estimated the VAR model as a 
last resort and constant model was used for the mean when no VAR models present statistically significant results was estimated. As mentioned before, the volatility models used in this study were estimated taking into consideration the student's $t$ distribution. Bivariate GARCH model is used for estimating the variance or volatility and covariance. VECH diagonal presented by Bollerslev, et al., (1988) is applied consisting of estimating the following equation as proposed by Ding and Engle (2001):

$H t=C+D \bullet e t-1 e t T-1+G \bullet H t-1$,

Accordingly is the Hadamard product and $\mathrm{Ht}$ represents the variance-covariance matrix at time t.

The bivariate case

\begin{tabular}{|c|c|c|c|c|c|}
\hline & $c_{11}$ & $d_{11}$ & 0 & 0 & ${ }^{e}{ }_{1} 2, t-1$ \\
\hline$h 11, t=$ & $c_{21}+$ & 0 & $d_{22}$ & 0 & - $e 2, t-11 e$ \\
\hline$h 21, t$ & $c_{22}$ & 0 & 0 & $d_{33}$ &,$t-1$ \\
\hline$h 22, t$ & & & & & $e_{2} 2, t-1$ \\
\hline
\end{tabular}

We applied three different models for mean. Model 1 was about the vector error correction (VEC) as represented by Engle and Granger (1987). Kroner and Sultan (1993) proposed the VEC form model utilized in this study.

$R S t=\alpha 1 S+\alpha 2 S(S t-1-\delta F t-1)+e S t$

$R F t=\alpha 1 F+\alpha 2 F(S t-1-\delta F t-1)+e F t \quad$,

where $S$ and $F$ refers to future and spot prices.

Vector autoregressive model is the second model used in this study presented in the econometric literature by Sims (1980). the VAR with lag one can be represented as follows;

$R S t=\alpha 11+\alpha 12 R S t-1+\alpha 13 R F t-1+e 1 t$

$R F t=\alpha 21+\alpha 22 R S t-1+\alpha 23 R F t-1+e 2 t$.

Constant model is the third model expressed as follows for the bivariate case:

$$
\begin{array}{lll}
r 1, t & a 1 & e 1, t \\
& = & + \\
r 2, t & a 2 & e 2, t .
\end{array} .
$$


by utilizing this, we can calculate the estimating Pearson product moment correlation through the following manner.

$\operatorname{cov}(e 1 t, e 2 t)$

$\operatorname{Var}(e 1 t) \operatorname{Var}(e 2 t)$

If efficient market hypothesis to be hold, the constant model and the Vector autoregressive models seems to be adequate. However, in case such hypothesis is not accepted, the cointegration variables must be included in the VAR model. Alternatively, the Vector Error Correction model seems to be more suitable. For each type of estimated models for constant, VAR and VEC average, different combinations were estimated among each of these models. The Schwarz criterio and Akaike criterion is chosen for selecting one to estimate the Pearson product moment correlation between stock returns and crude oil returns. This way each of the selected bivariate models showed statistical significance for all parameters estimated and lower AIC and BIC criterion. The empirical results obtained are presented below.

\section{RESULTS}

The following table 3 provide the details about tau-statistics and p value for the stock market return of selected stock in Indian economic sector and the crude oil price returns cointegration. BOVESPA index and BMF are also presented for crude oil price returns cointegration test results. The results are based on crude oil price return treating as an independent variable in the cointegration test used here, the Engle Granger test. The null hypothesis of the test is non-cointegration among selected firms returns and IBVSP and crude oil returns.

Table 3

Cointegration Test Results

\begin{tabular}{lll}
\hline Time Series Returns & tau-statistic & p value \\
\hline ALLL & -11.5655 & 0.0000 \\
AMBV & -14.5848 & 0.0000 \\
CMIG & -10.1444 & 0.0000 \\
CSNA & -4.34434 & 0.0000 \\
CYRE & -09.8888 & 0.0000 \\
ITUB & -43.4445 & 0.0000 \\
PCAR & -09.3343 & 0.0000 \\
PETR & -5.45458 & 0.0000 \\
VALE & -31.44443 & 0.0000 \\
IBVSP & -6.4433 & 0.0000 \\
\hline
\end{tabular}


The analysis of cointegration test shows that as the lower values of statistical tau the lower the probability to make an error by accepting the hypothesis of cointegration between the involved variables, this probability are given by $\mathrm{p}$ value. The result shows that all alternative hypotheses are accepted and null hypotheses are rejected. It shows that when the equity returns, or the IBVSP was used as an independent variable int eh test, the results are the same. Hence, the error correction mechanism need to be introduced in the VAR models as suggested by these results. Furthermore, for equity and crude oil markets, the efficient market hypothesis cannot be accepted.

The following table 4 presents the results of Granger causality test. The null hypothesis under this test is that crude oil price returns does not cause the stock price returns which is the equity price returns or the BMF and Bovespa index return. The results shows that the null hypothesis could not be rejected as the number of lags used in the tests are decreasing, so the crude oil price returns does not cause the IBVSP and all equity returns time series analyzed in the work. However, it is important to mention that as the number of lags increases, the probability of rejection will be decreasing. Because of daily returns are the data used, we can infer that a causal relationship exists, however, mostly it is not occurring rapidly but about two months gap.

The VECH diagonal was the selected volatility model based on three different average model estimates. VEC was the first average in the first model. Vector autoregressive was based on the second model. The last option is the constant model for the average. The variance equation was an $\mathrm{ARCH}$ model based on matrix $\mathrm{C}$ and $\mathrm{D}$ assuming the possibilities including full rank, one rank, undefined, diagonal, and scalar. The models were estimated with all possible combination of these possibilities for variations in both matrices and then observed the results obtained. The student $\mathrm{t}$ distribution range was between 2 to 8 . Mostly, the bivariate models were the VEC models. The models which considered the firm CMIG, CSNA, PCAR and Vale the average estimation was made using a constant model while the VAR model was used for the firm ALLL.

Table 4

Causality Test Results

\begin{tabular}{|c|c|c|c|c|c|c|c|c|}
\hline \multicolumn{9}{|l|}{ Lags } \\
\hline & 2 & 5 & 10 & 20 & 40 & 40 & 50 & 50 \\
\hline Equity & & & & & & & & \\
\hline & 0. & 0.9979 & 1.14444 & 1.4444 & 1.9999 & 1.4444 & 1.5455 & 1.9979 \\
\hline & $(0.5555)$ & $(0.4445)$ & $(0.4444)$ & $(0.4444)$ & $(0.0454)$ & $(0.0004)$ & $(0.0001)$ & (0.0001) \\
\hline & 4.0114 & 1.4490 & 0.7944 & 0.9455 & 0.4440 & 1.1444 & 1.4544 & 1.4445 \\
\hline
\end{tabular}




\begin{tabular}{|c|c|c|c|c|c|c|c|c|}
\hline & $(0.4541)$ & $(0.4945)$ & $(0.5159)$ & $(0.5415)$ & $(0.5745)$ & $(0.4591)$ & $(0.1475)$ & 0.0545 \\
\hline & 0.1441 & 0.4454 & 1.9745 & 1.4445 & 1.1444 & 1.4497 & 1.5541 & 1.4547 \\
\hline CMIG & $(0.7750)$ & (0.9977) & $(0.4441)$ & $(0.4454)$ & $(0.5547)$ & $(0.45545)$ & $(0.0594)$ & $(0.0455)$ \\
\hline & 0.144 & 0.1444 & 0.5544 & 1.4444 & 1.9999 & 1.4450 & 1.5454 & 1.5554 \\
\hline \multicolumn{9}{|l|}{ CSNA } \\
\hline & $(0.9551)$ & $(0.9957)$ & $(0.7404)$ & $(0.4171)$ & $(0.1447)$ & $(0.0544)$ & (0.0059) & $(0.0050)$ \\
\hline & 0.0754 & 0.1997 & 0.4444 & 0.7549 & 0.9554 & 0.9551 & 1.1444 & 1.1557 \\
\hline CYRE & $(0.4549)$ & $(0.4459)$ & $(0.7979)$ & $(0.9444)$ & $(0.5457)$ & $(0.5451)$ & (0.9999) & $(0.4499)$ \\
\hline & 0.4549 & 1.1444 & 0.5444 & 1.4457 & 1.7551 & 1.7555 & 1.5444 & 1.4450 \\
\hline ITUB & $(0.4444)$ & $(0.444)$ & $(0.454)$ & $(0.545)$ & (0.0997) & $(0.0090)$ & $(0.0054)$ & $(0.0014)$ \\
\hline \multirow{3}{*}{ PCAR } & 0.5444 & 0.4515 & 0.9907 & 0.9491 & 0.9404 & 1.1195 & 1.1444 & 1.1557 \\
\hline & $(0.5411)$ & $(0.9144)$ & $(0.4495)$ & $(0.5479)$ & $(0.5750)$ & $(0.4951)$ & $(0.4455)$ & $(0.1995)$ \\
\hline & 1.1191 & 1.1547 & 0.9547 & 1.0445 & 0.9591 & 1.0049 & 1.1549 & 1.1091 \\
\hline \multicolumn{9}{|l|}{ PETR } \\
\hline & $(0.4474)$ & $(0.4445)$ & $(0.4747)$ & $(0.4149)$ & $(0.5404)$ & $(0.4555)$ & $(0.4417)$ & 0.4745 \\
\hline & 0.9194 & 0.9911 & 0.9549 & 0.9109 & 1.0455 & 1.0457 & 1.4159 & 1.0994 \\
\hline VALE & $(0.4445)$ & $(0.4440)$ & $(0.4441)$ & $(0.5444)$ & $(0.4499)$ & $(0.5550)$ & $(0.4495)$ & $(0.5597)$ \\
\hline & 0.5510 & 0.4579 & 0.4444 & 1.4404 & 1.4475 & 1.4401 & 1.4494 & 1.4444 \\
\hline
\end{tabular}

We can make the inference that there are similar behavior evolutions of correlation coefficients estimated for almost any analyzed time series. The only exception was correlation coefficient estimated for the Brent returns and the firm which representing the electric energy sector, CEMIG, and the firm which representing the mining sector, VALE.

Observing the graphic results shown in Figure 1, it can be inferred that there are similar behavior evolutions of correlation coefficients estimated for almost any analyzed time series. The exception of the correlation coefficients estimated to study the association of the Brent returns and the firm that represent the electric energy sector, CEMIG, and the firm that represent the mining sector, VALE.

The Indian capital market is another exception in this regard. While, the connection between crude oil prices return, we observed a lower coefficient of less than 0.4 for VALE which indicated that there is weak but positive relationship between mining sector returns and crude oil price returns. For the connection between electric energy sector returns, the crude oil price returns was about 0.21 with maximum of 0.24 , lower than VALEs. Overall, we infer that for Indian capital market is strongly associated with the international oil market.

It can also be observed that from September 2008, all international financial crisis emerged. The height of the financial crisis was late 2008 and early 2009 presenting a decrease in the association between the crude oil price returns time series and the Indian capital market returns time series studied in this study. The results of dynamic correlation coefficients are 
presented in the table 5. Result shows that PETR and CSNA which representing the petroleum and steel industry have the highest average of correlations estimated followed closely by CYRE and ITUB which represents respectively the financial sector and the banking sector.

\section{CONCLUSION}

The objective of the study was to test the relationship between the Indian stock market price and the crude oil prices return. Findings based on cointegration and causality association shows that equity time series are cointegrated with Brent crude oil prices returns. The results also conclude that time series have a long run interaction.

\section{References}

Basher, S. and Sadorsky, P. (2006). Oil Price Risk and Emerging Stock Markets. Global Finance Journal,17, 224-251.

Bhunia, A. (2012). Association between Crude Price and Stock Indices: Empirical Evidence from Bombay Stock Exchange. Journal of Economics and Sustainable Development,3(3), 25-34.

Bollerslev, T., Engle E, R. F., \& Wooldridge, J. M. (1988). A Capital Asset Pricing Model with Time-Varying Covariances. The Journal of Political Economy, 96(1), 116-131.

Chen, N., Roll, R., \& Ross, S. (1986). Economic Forces and the Stock Market. Journal of Business, 59(3), 383-403.

Ding, Z., \& Engle, R. (2001). Large Scale Conditional Covariance Matrix Modeling, Estimation and Testing. Available: http://ssrn.com/abstract=1296437.

Engle, R., \& Granger, C. (1987) Cointegration and Error Correction: Representation, Estimation, and Testing. Econometrica, 55(2), 251-276.

Fall, R., \& Brailsford, T. (1999). Oil Price Risk and the Australian Stock Market. Journal of Energy Finance and Development,4, 69-87.

Farahani, G. Y., Ghara, A. E., Sadr, S. (2012). Is Cointegration between Oil Price and Economic Growth? Case Study Iran. Procedia - Social and Behavioral Sciences, 62, 1215-1219.

Ferson, W., \& Harvey, C. (1995). Predictability and Time-Varying Risk in World Equity Markets. Research in Finance, 13, 25-88.

Granger, C. (1969). Investigating Causal Relations by Econometric Models and CrossSpectral Methods. Econometrica, 37(3), 424-438.

Hamao, Y. (1989). An Empirical Examination of the Arbitrage Pricing Theory: Using Japanese Data. Japan and the World Economy, 1(1), 45-61.

Hammoudeh, S., \& Eleisa, L. (2004). Dynamic Relationship among GCC Stock Markets and NYMEX Oil Futures. Contemporary Economic Policy, 22, 250-269.

Hammoudeh, S., Dibooglu, S., \& Aleisa, E. (2004). Relationships among U.S. Oil Prices and Oil Industry Equity Indices. International Review of Economics and Finance, 13, 427-453. 
Henriques, I., \& Sadorsky, P. (2008). Oil Prices and the Stock Prices of Alternative energy Companies. Energy Economics, 30(3), 998-1010.

Huang, A., Hu, W., Cheng, C., \& Chen, C. (2011). Relationship between Crude Oil Prices of Alternative Energy Companies with Recent Evidence. Economic Bulletin, 31(3), 2434-2443.

Jones, C., \& Kaul, G. (1996). Oil and Stock Markets. Journal of Finance, 51(2), 463-491.

Kroner, F., \& Sultan, J. (1993). Time Varying Distribution and Dynamic Hedging with Foreign Currency Futures. Journal of Financial and Quantitative Analysis, 28(4), 535-551.

Maghyereh, A. (2004). Oil Price Shocks and Emerging Stock Markets: A Generalized VAR Approach. International Journal of Applied Econometrics and Quantitative Studies, 1(2), 27-40.

Nandha, M., \& Faff, R. (2008). Does Oil Move Equity Prices? A Global View. Energy Economics, 30(3), 986-997.

Papapetrou, E. (2001). Oil Price Shocks, Stock Markets, Economic Activity and Employment in Greece. Energy Economics, 23(5), 511-532.

Ratti, R., \& Hasan, M. (2013). Oil Price Shocks and Volatility in Australian Stock Returns. Munich Personal RePEc Archive - MPRA Paper No. 49043, Available: http://mpra.ub.unimuechen.de/49043/.

Sadorsky, P. (1999). Oil Price Shocks and Stock Market Activity. Energy Economics, 21(5), 449-469.

Sadorsky, P. (2003). The Macroeconomic Determinants of Technology Stock Price Volatility. Review of Financial Economics, 12(2), 191-205.

Sims, C. (1980). Macroeconomics and Reality. Econometrica,48(1), 1-48.

Tansuchat, R., Chang, C., \& McAleer, M. (2010). Conditional correlations and Volatility Spillovers between Crude Oil and Stock Index Returns. Available: http://ssrn.com/abstract=1534043. 